\title{
Effect of Trimethyl Chitosan with Different Degrees of Quaternization on the Properties of Tablets Prepared using Charged Model Drugs
}

\author{
Supavadee BOONTHA ${ }^{1, *}$, Duangdau JAICHUM ${ }^{1}$, Kannikar KUNSEANG ${ }^{1}$, \\ Korrakrit WANJAI ${ }^{1}$, Worawan BOONYO ${ }^{2}$ and Tasana PITAKSUTEEPONG \\ ${ }^{1}$ School of Pharmaceutical Sciences, University of Phayao, Phayao 56000, Thailand \\ ${ }^{2}$ Department of Technical Pharmacy Program, Sirindhorn Collage of Public Health Phitsanulok, \\ Phitsanulok 65130, Thailand \\ ${ }^{3}$ Department of Pharmaceutical Technology, Faculty of Pharmaceutical Sciences, Naresuan University, \\ Phitsanulok 65000, Thailand
}

('Corresponding author's e-mail: supa0865@hotmail.com)

Received: 16 April 2020, Revised: 3 February 2021, Accepted: 5 March 2021

\begin{abstract}
Trimethyl chitosan (TMC) has demonstrated effectiveness as an absorption enhancer for hydrophilic and high molecular weight (MW) drugs across the intestinal epithelium. However, the effects of degrees of quaternization (DQ) of TMC on the absorption of negatively and positively charged drugs have not been investigated. This investigation aimed to determine the properties of the tablets formulated using TMC with different DQ. In this study, TMC with DQ of $20 \%$ (TMC-20), $40 \%$ (TMC-40) and $60 \%$ (TMC-60) were synthesized and subsequently characterized. Cetirizine dihydrochloride (CHC) and hyoscine butylbromide (HBB) were used as negatively and positively charged model drugs. Eight tablet formulations were prepared using the wet granulation method. The formulated tablets were evaluated regarding their properties in terms of thickness and hardness, weight variation, disintegration time, and dissolution profile. These tablets were evaluated according to the standards set by the United States Pharmacopeia (USP41) guidelines. The results showed that TMC with all DQ have the MW and an intrinsic viscosity less than starting chitosan. The MW and an intrinsic viscosity of the synthesized TMC decreased with increasing DQ. In order to evaluate the effect of TMC with various DQ on the properties of the formulated tablets, all tablet formulations prepared had good characteristics and were found to be within the acceptable range based on the requirements of USP. In conclusion, TMC had a minor retarding effect on the dissolution profiles of $\mathrm{CHC}$ from the formulated tablets. Still, TMC was able to significantly delay the release of HBB from the formulated tablets $(p>0.05)$. When TMC with various DQ were compared, TMC-60 showed higher drug release than TMC-20 and TMC-40. In our study, we observed a possible interaction between the model drugs and TMC. This warrants the need for further studies.
\end{abstract}

Keywords: Absorption enhancers, Cetirizine dihydrochloride, Dissolution profiles, Hyoscine butylbromide, Intrinsic viscosity

\section{Introduction}

Generally, drugs in ionized form or drugs with charge have difficulty penetrating the membrane of gastrointestinal (GI) epithelium cells due to the high electrical resistance and low solubility in lipids [1]. Consequently, low absorption and bioavailability of the charged drugs administered through the oral route are observed [2]. To overcome this limitation of the charged drug, an absorption enhancer is necessary.

Trimethyl chitosan (TMC), a synthesized polymer obtained by the partially quaternized chitosan, is gaining interest as pharmaceutical and non-pharmaceutical excipients [3]. Compared with chitosan, TMC 
http://wjst.wu.ac.th

has higher water solubility, even in a neutral $\mathrm{pH}$ medium, while chitosan is only soluble in an acidic $\mathrm{pH}$ medium [3-6]. TMC has demonstrated effectiveness as an absorption enhancer for hydrophilic and high molecular weight drugs across the intestinal epithelium. Using the exact mechanism of chitosan, TMC showed the ability to redistribute the cytoskeletal F-actin and the zonula occludens-1 (ZO-1) to open tight junctions and cross epithelial barriers [6,7] TMCs with different DQ have been synthesized and investigated for their properties, such as permeation enhancement, colonic delivery, nasal delivery and DNA delivery $[3,8]$. The DQ, representing the charge density of TMC, has been reported to affect the ability of TMC on the enhancement of drug absorption across the GI tract [6-9]. However, the effects of DQ of TMC on the absorption of negatively and positively charged drugs have not been investigated. Therefore, the effects of TMC with different DQ on the properties and dissolution profiles of tablets formulated using charged model drugs were investigated in this study. CHC and HBB were chosen as negatively and positively charged model drugs in this study. Their characteristics are shown in Table 1. $\mathrm{CHC}$, a long-acting, non-sedative antihistamine, is generally used to treat various allergic symptoms for hay fever and chronic urticarial [10-12]. CHC is highly adsorbed and has high systemic bioavailability (70\%) after oral administration [13]. HBB, an antispasmodic drug, is usually used to treat abdominal pain associated with cramps from GI spasms. After oral administration, HBB is poorly adsorbed (8\%) and has low systemic bioavailability $(1 \%)[14,15]$. These charged model drugs and TMC with various DQ were formulated in tablet dosage forms. The prepared tablets were evaluated for thickness, hardness, weight variation, and disintegration time as drug dissolution is a crucial step for drug absorption after oral administration [16]. Thus, the dissolution profiles were also determined.

Table 1 Characteristics of the charged model drugs.

\begin{tabular}{cccccc}
\hline Drug & Formula & $\mathbf{M W}(\mathbf{g} / \mathbf{m o l})$ & Water solubility & Chemical structure & Reference \\
$\begin{array}{c}\text { Cetirizine } \\
\text { dihydrochloride }\end{array}$ & $\mathrm{C}_{21} \mathrm{H}_{27} \mathrm{Cl}_{3} \mathrm{~N}_{2} \mathrm{O}_{3}$ & 461.8 & Freely soluble \\
$\begin{array}{c}\text { Hyoscine } \\
\text { butylbromide }\end{array}$ & $\mathrm{C}_{21} \mathrm{H}_{30} \mathrm{BrNO}_{4}$ & 440.4 & Freely soluble \\
\hline
\end{tabular}

\section{Materials and methods}

\section{Materials}

$\mathrm{CHC}$ and $\mathrm{HBB}$ were provided by Bangkok Lab and Cosmetics Co, Ltd (Ratchaburi, Thailand). Corn starch, lactose, magnesium stearate, and talcum were obtained from Union Science Co. Ltd. (Chiang Mai, Thailand).

\section{Synthesis and characterization of synthesized TMC}

TMC samples with DQ of $20 \%$ (TMC-20), $40 \%$ (TMC-40) and $60 \%$ (TMC-60) were synthesized by reductive methylation of chitosan with $\mathrm{MW}$ of $160 \mathrm{kDa}$ (intrinsic viscosity $=8.90 \mathrm{~mL} / \mathrm{g}$ ), as previously described [17]. In brief, TMC with DQ of $20 \%$ was prepared with a single reaction step (1R). 
http://wjst.wu.ac.th

Chitosan was suspended in a mixture of sodium iodide, $20 \% \mathrm{w} / \mathrm{v}$ aqueous sodium hydroxide and Nmethyl-2-pyrrolidone (NMP). After the mixture was heated to $60{ }^{\circ} \mathrm{C}$ for $20 \mathrm{~min}$, methyl iodide was added and the reaction was carried out for $30 \mathrm{~min}$. Diethyl ether was added to the solution 3 times to obtain the precipitated TMC.

TMC samples with DQ of 40 and $60 \%$ were prepared with 1 reaction step followed by a single (1R1A) or 2 (1R2A) additional steps, respectively. In brief, an additional step was performed by adding a mixture of methyl iodide and aqueous sodium hydroxide before precipitation of the obtained TMC at the end of the reaction step. The reaction was further continued at $60{ }^{\circ} \mathrm{C}$ for $30 \mathrm{~min}$. Subsequently, the resulting TMC solution was precipitated by adding diethyl ether 3 times. After removing iodide ions by ion-exchange with chloride ions, the synthesized TMC was lyophilized (Dura-Dry ${ }^{\mathrm{TM}_{\text {Series, }}}$ FTSSYSTEMS, USA) and then stored in light-protected desiccators for further use.

The DQ, indicating the charge density of the synthesized TMC obtained, was characterized by ${ }^{1} \mathrm{H}-$ Nuclear magnetic resonance spectroscopy ( $\left.{ }^{1} \mathrm{H}-\mathrm{NMR}\right)$ (AV400, Bruker, Denmark). Deuterium oxide $\left(\mathrm{D}_{2} \mathrm{O}\right)$ was used as a solvent. The DQ was calculated using the following equation:

$\% \mathrm{DQ}=\left\{\left[\left[\left(\mathrm{CH}_{3}\right)_{3}\right] /[\mathrm{H}]\right] \times 1 / 9\right\} \times 100$

where $\% \mathrm{DQ}$ is the percentage for the degree of quaternization, $\left[\left(\mathrm{CH}_{3}\right)_{3}\right]$ is integral for the chemical shift of the trimethyl amino groups at $3.3 \mathrm{ppm}$, and [ $\mathrm{H}$ is the integral for the ${ }^{1} \mathrm{H}$ peak between $4.7-5.7 \mathrm{ppm}$, as shown in Figure 1.

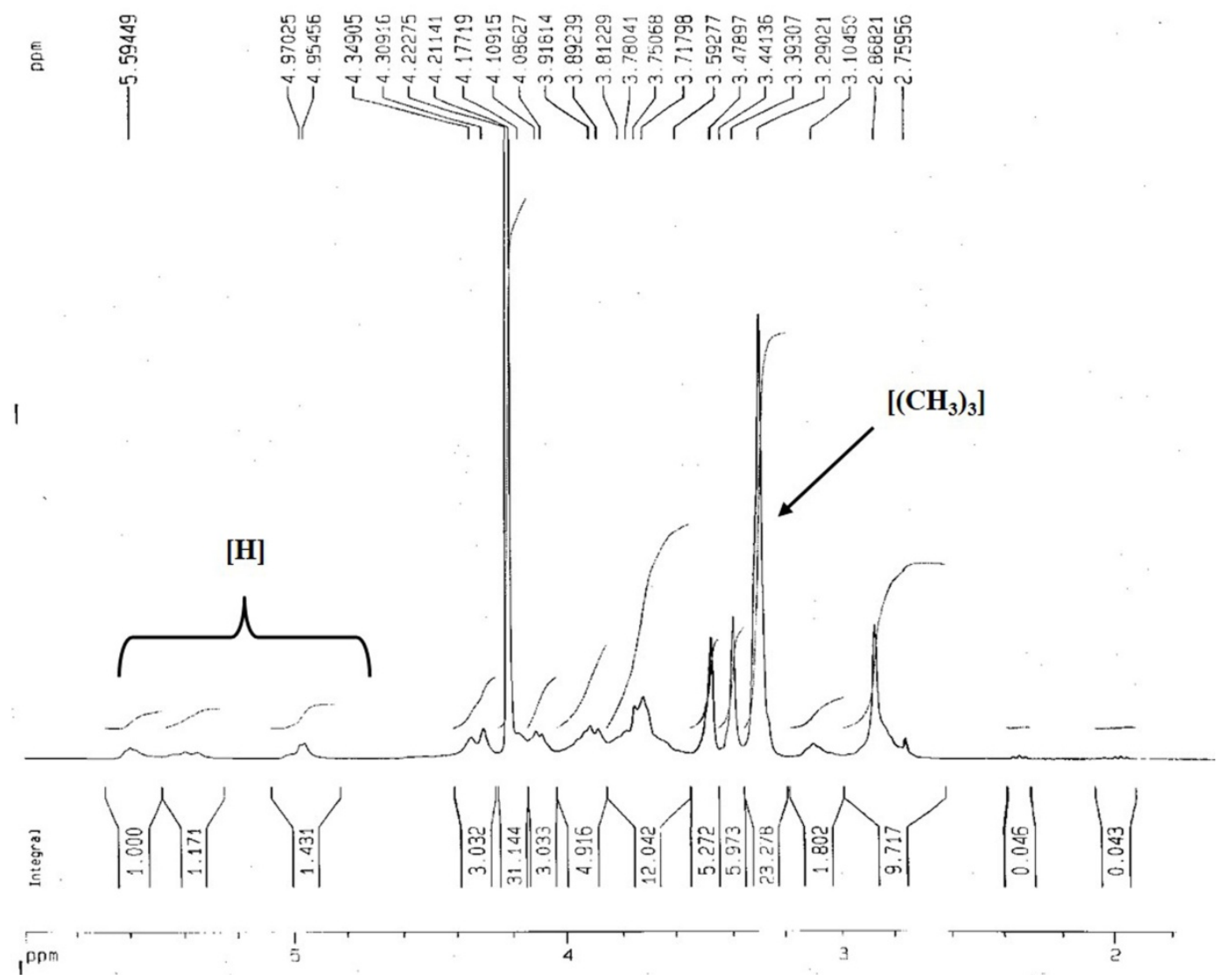

Figure $1{ }^{1}$ H-NMR spectra of synthesized TMC [18]. 
http://wjst.wu.ac.th

The average MW of the synthesized TMC was characterized by gel permeation chromatography (GPC) (Waters 600E, Waters Co., USA). In brief, $2 \mathrm{mg} / \mathrm{mL}$ of a sample solution in acetate buffer (pH 3) was prepared and then filtered through $0.45 \mu \mathrm{m}$ nylon membrane filters. The assay was performed with ultrahydrogel linear columns (MW resolving range $=1,000-20,000,000$ ). Sample solutions with a volume of $20 \mu \mathrm{L}$ were analyzed with a refractive index detector. The mobile phase comprises of an acetate buffer $(\mathrm{pH} \mathrm{3})$. A flow rate was run at $0.6 \mathrm{~mL} / \mathrm{min}$. The standards used to calibrate the column were pullulans (MW 5,800 - 780,000).

The intrinsic viscosities of the synthesized TMC were characterized by an Ostwald-Cannon-Fenske viscometer (No 75, DC Specific Glass, Maryland, USA). In brief, TMC solutions with various concentrations were prepared. The TMC solutions were kept at $20{ }^{\circ} \mathrm{C}$ in a water bath throughout the experimental study. The solvent used in the study was water. Then, the flow time for each solution $(t)$ and solvent $\left(t_{0}\right)$ was measured using the viscometer. The relative viscosity $\left(\eta_{\text {rel }}\right)$ of the solution sample was determined using the following equation:

$\eta_{\text {rel }}=\frac{t}{t_{0}}$

The specific viscosity $\left(\eta_{\mathrm{sp}}\right)$ of the sample solution was determined by the following equation;

$\eta_{\mathrm{sp}}=\eta_{\mathrm{rel}}-1$

A graph was plotted between $\eta_{\mathrm{sp}} / c$ against the concentration of the sample solution $(c)$. The intrinsic viscosity $([\eta])$ was obtained by extrapolation to the value of null concentration.

Preparation and evaluation of tablet properties

The tablets containing the model drugs, including $\mathrm{CHC}$ and $\mathrm{HBB}$, were prepared by the wet granulation method. The composition of the tablet formulations consisted of TMC with various DQ as an absorption enhancer, $10 \%(\mathrm{w} / \mathrm{w})$ starch paste as a binder, and corn starch as a disintegrant. Magnesium stearate and talcum acted as lubricants while lactose served as a filler. The compositions of the tablet formulations are shown in Table 2.

Table 2 Compositions of the tablet formulations.

\begin{tabular}{|c|c|c|c|c|c|c|c|c|}
\hline \multirow{2}{*}{ Compositions } & \multicolumn{8}{|c|}{ Amount (mg/tablet) } \\
\hline & Rx-1 & $\mathbf{R x}-2$ & $\mathbf{R x}-\mathbf{3}$ & Rx-4 & $\mathbf{R x}-5$ & Rx-6 & Rx-7 & Rx-8 \\
\hline $\mathrm{CHC}$ & 10 & 10 & 10 & 10 & - & - & - & - \\
\hline HBB & - & - & - & - & 10 & 10 & 10 & 10 \\
\hline TMC-20 & - & 0.5 & - & - & - & 0.5 & - & - \\
\hline TMC-40 & - & - & 0.5 & - & - & - & 0.5 & - \\
\hline TMC-60 & - & - & - & 0.5 & - & - & - & 0.5 \\
\hline Starch paste & \multicolumn{8}{|c|}{$0.19 \mathrm{mg} /$ tablet } \\
\hline Corn starch & \multicolumn{8}{|c|}{$15.0 \mathrm{mg} /$ tablet } \\
\hline Magnesium stearate & \multicolumn{8}{|c|}{$0.0040 \mathrm{mg}$ /tablet } \\
\hline Talcum & \multicolumn{8}{|c|}{$0.0012 \mathrm{mg} /$ tablet } \\
\hline Lactose add to & \multicolumn{8}{|c|}{$150.0 \mathrm{mg} /$ tablet } \\
\hline
\end{tabular}


http://wjst.wu.ac.th

The ingredients were weighed individually and then mixed in a mortar using geometric dilution technique. The TMC was dissolved in a binder solution before it was mixed with other ingredients. Then, the resulting damp mass was passed through sieve no.14. The prepared wet granules were dried at $50{ }^{\circ} \mathrm{C}$ in a hot-air oven (Memmert, Schwabach, Germany) for $4 \mathrm{~h}$. Subsequently, dry granules were passed through sieve no.18 and then lubricated with magnesium stearate and talcum. The batch size for the entire tablet formulation was 150 tablets. A hydraulic press (PerkinElmer, IL, USA) was used to prepare the tablets using a round, flat-faced punch with a diameter of $6.35 \mathrm{~mm}$ at a compaction force of $1.5 \mathrm{kN}$. The obtained tablets were further evaluated for thickness, hardness, weight variation, disintegration time, and dissolution profile according to the method described in USP41 [19].

\section{Thickness and hardness}

The thickness and hardness of the ten tablets were measured individually using a thickness hardness tester (Erweka, Germany). Data were recorded as mean $\pm \mathrm{SD}$ in $\mathrm{mm}$ for thickness and kilopond (KP) for hardness.

\section{Weight variation}

Twenty tablets were accurately weighed individually using a 4-digit analytical balance (Adam, United Kingdom). The acceptable percentage for weight variation was in the range of $\pm 7.5 \%$.

\section{Disintegration time (DT)}

Six tablets were tested using a disintegration tester (Erweka, Germany). Distilled water was used as a medium and controlled temperature at $37 \pm 2{ }^{\circ} \mathrm{C}$. The acceptable DT was not more than 15 min as per the British Pharmacopoeia [20].

\section{Dissolution test}

In vitro dissolution test of the prepared tablets was carried out using the USP apparatus II (Erweka ${ }^{\circledR}$, Heusenstamm, Germany). The paddle speed was set at 50 revolutions per min (rpm). Purified water with a volume of $900 \mathrm{~mL}$ was used as a dissolution medium and the temperature was maintained at $37 \pm 0.5^{\circ} \mathrm{C}$. Six tablets were tested for each formulation. Aliquots of the samples were manually withdrawn at the determined time intervals and were replaced with an equal volume of fresh dissolution medium. Thereafter, the samples were filtered and diluted with the dissolution medium to obtain the working concentration. The amount of drug released was analyzed using a UV spectrophotometer (JASCO V$630^{\circledR}$, UK) at wavelengths of 230 and $610 \mathrm{~nm}$ for $\mathrm{CHC}$ and $\mathrm{HBB}$, respectively. The amount of drug released was also calculated using an equation obtained from the standard curve. Finally, the percentage of the cumulative drug release was reported.

\section{Statistical analysis}

The data values were expressed as mean \pm SD. One-way analysis of variance (ANOVA) with post hoc LSD test was performed using Sigma Stat software version 3.5 (Systat Software Inc., San Jose, CA, USA). A $p$-value of less than 0.05 was considered a statistically significant difference.

\section{Results and discussion}

The characteristics of synthesized TMC prepared

The characteristics of the synthesized TMC prepared are shown in Table 3. The synthesized TMC obtained had approximately 20, 40 and $60 \%$ DQ. All synthesized TMC have MW and intrinsic viscosity less than the starting chitosan. The MW and intrinsic viscosity of synthesized TMC decreased with increasing DQ. These results obtained may be explained by the degradation of the polymer backbone occurred in the synthesis reaction step [17]. In addition, the intrinsic viscosity is directly proportional to the MW according to the Mark-Houwink equation [21,22]. Therefore, the MW and intrinsic viscosity of synthesized TMC decreased in the following order: Chitosan > TMC-20 > TMC-40 > TMC-60. 
http://wjst.wu.ac.th

Table 3 The molecular weight and intrinsic viscosity of the starting chitosan and the synthesized TMC.

\begin{tabular}{ccc}
\hline Polymers & Molecular weight (kDa) & Intrinsic viscosity (mL/g) \\
\hline Chitosan & 160 & 8.9 \\
TMC-20 & 130 & 6.1 \\
TMC-40 & 110 & 3.9 \\
TMC-60 & 85 & 3.1 \\
\hline
\end{tabular}

\section{Properties of the formulated tablets}

As shown in Figure 2, the formulated tablets were white and exhibited good characteristics. Their properties are shown in Table 4. The tablets had a flat surface with a round shape of $6.35 \pm 0.01 \mathrm{~mm}$ in diameter. The thickness of the tablets was approximately $3.22 \pm 0.02 \mathrm{~mm}$. The tablet hardness ranged between $12.73-20.36 \mathrm{KP}$, indicating that it might be strong enough to avoid friability during packaging and transportation. By using TMC with various DQ for $\mathrm{CHC}$ and $\mathrm{HBB}$, the tablet hardness increased with increasing DQ. However, the tablet hardness of all formulations was not significantly different $(p>0.05)$. The tablet weight was in a range between $148.10-149.70 \mathrm{mg}$, which was not more than $7.5 \%$ of the target weight of $150 \mathrm{mg}$. The formulated tablets showed a narrow weight variation range with a percentage weight variation of less than $2 \%$. For disintegration time, the $\mathrm{CHC}$ tablets disintegrated slower than the HBB tablets. This may be attributed to a higher degree of hardness in the CHC tablets when compared to the HBB tablets, as shown in Table 4. However, all of the formulated tablets were completely disintegrated within $10 \mathrm{~min}$. Therefore, the formulated tablets were found to be acceptable under the requirements of the USP41 standard.

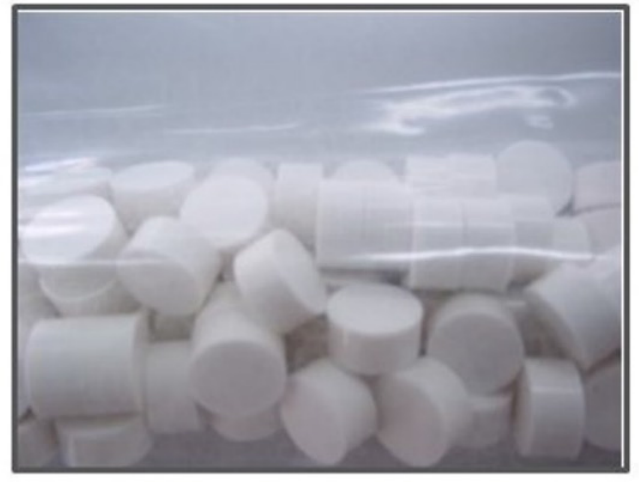

(a)

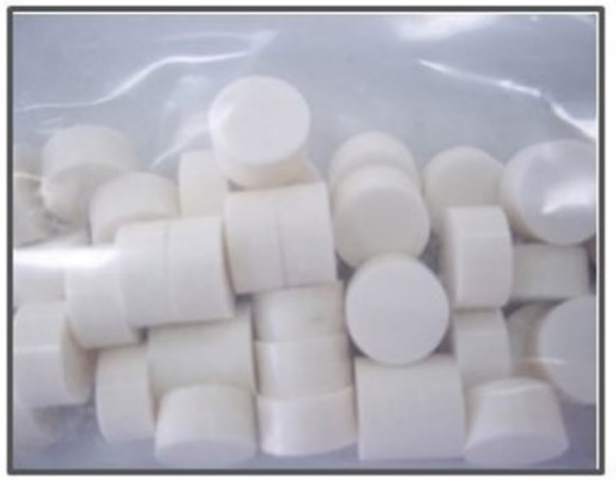

(b)

Figure 2 The physical appearance of the CHC tablets (a) and HBB tablets (b). 
http://wjst.wu.ac.th

Table 4 Evaluation parameters of the formulated tablets.

\begin{tabular}{ccccccc}
\hline $\begin{array}{c}\text { Product } \\
\text { Code }\end{array}$ & Formulation & $\begin{array}{c}\text { Thickness } \\
(\mathbf{m m})\end{array}$ & $\begin{array}{c}\text { Hardness } \\
\mathbf{( K P )}\end{array}$ & $\begin{array}{c}\text { Weight } \\
\text { variation }(\mathbf{m g})\end{array}$ & $\begin{array}{c}\text { Weight variation } \\
\mathbf{( \% )}\end{array}$ & $\begin{array}{c}\text { DT } \\
(\mathbf{m i n})\end{array}$ \\
\hline $\mathrm{Rx}-1$ & $\mathrm{CHC}$ & $3.23 \pm 0.01$ & $19.50 \pm 1.16$ & $148.50 \pm 0.70$ & 0.54 & $5.03 \pm 0.24$ \\
$\mathrm{Rx}-2$ & $\mathrm{CHC}+\mathrm{TMC}-20$ & $3.24 \pm 0.02$ & $20.36 \pm 1.70$ & $149.30 \pm 1.50$ & 1.00 & $5.15 \pm 0.32$ \\
$\mathrm{Rx}-3$ & $\mathrm{CHC}+\mathrm{TMC}-40$ & $3.24 \pm 0.02$ & $20.06 \pm 1.16$ & $149.60 \pm 1.20$ & 0.87 & $5.33 \pm 0.35$ \\
$\mathrm{Rx}-4$ & $\mathrm{CHC}+\mathrm{TMC}-60$ & $3.24 \pm 0.02$ & $18.99 \pm 1.22$ & $149.70 \pm 1.00$ & 0.87 & $5.65 \pm 0.35$ \\
$\mathrm{Rx}-5$ & $\mathrm{HBB}$ & $3.20 \pm 0.02$ & $12.73 \pm 1.24$ & $148.10 \pm 1.30$ & 1.35 & $4.25 \pm 0.56$ \\
$\mathrm{Rx}-6$ & $\mathrm{HBB}+\mathrm{TMC}-20$ & $3.19 \pm 0.03$ & $14.62 \pm 1.51$ & $148.50 \pm 1.30$ & 0.94 & $5.46 \pm 0.34$ \\
$\mathrm{Rx}-7$ & $\mathrm{HBB}+\mathrm{TMC}-40$ & $3.21 \pm 0.03$ & $13.27 \pm 1.28$ & $148.70 \pm 1.00$ & 0.40 & $3.92 \pm 0.32$ \\
$\mathrm{Rx}-8$ & $\mathrm{HBB}+\mathrm{TMC}-60$ & $3.20 \pm 0.04$ & $13.13 \pm 1.74$ & $148.60 \pm 1.60$ & 1.14 & $3.79 \pm 0.34$ \\
\hline
\end{tabular}

\section{Dissolution study}

Using $\mathrm{CHC}$ as a model drug, the dissolution of the formulated tablets without TMC showed more rapid drug release than the tablets formulated with TMC-40, TMC-20, and TMC-60 (Figure 3a). This may be due to ionic interaction between $\mathrm{CHC}$ and $\mathrm{TMC}$, which might result in delayed $\mathrm{CHC}$ release from the formulated tablets. Also, TMC polymers were less water-soluble than lactose. The drug release from the formulated tablet with TMC was retarded, possibly due to the higher viscous gel layer of TMC polymer that might have affected the drug release [23]. As shown in Table 3, the intrinsic viscosity of synthesized TMC decreased with increasing DQ. A delay in drug release was observed with CHC tablets formulated using TMC-20, TMC-40, and TMC-60. Moreover, there was no statistical significance between the model drug and the formulated tablets concerning their cumulative percentage release $(p>$ $0.05)$.

A similar release profile was observed for $\mathrm{HBB}$. At $60 \mathrm{~min}$, the amount of $\mathrm{HBB}$ released from the tablets prepared without TMC and those from the tablets prepared with TMC-20, TMC-40, and TMC-60 were approximately $80,40,50$, and $60 \%$, respectively. The dissolution of tablets prepared without TMC showed more rapid drug release than the tablets prepared with the presence of TMC. Moreover, a significantly decreased dissolution of HBB was found in the tablet formulated with the presence of TMC $(p<0.05)$ (Figure 3b). Again, these results may be attributed to the higher water solubility of lactose than TMC polymers and also may be due to the interaction between HBB and TMC. Thus, the above factors might result in a delayed release of HBB from the formulated tablet. Auspiciously, these results agree with the results of our previous study, which reported that neostigmine bromide, a drug with a positive charge, might interact with TMC, resulting in retarded drug release from the prepared tablet [24]. Owing to a better water solubility and lower viscosity, TMC with DQ of $60 \%$ showed higher drug release from the formulated tablet when compared to the tablets formulated with TMC-20 and TMC-40. As the 2 model drugs are freely soluble in water, their water solubility does not account for the delayed dissolution effect. The interaction between HBB and TMC will be determined in future studies.

The drug release from the $\mathrm{CHC}$ and $\mathrm{HBB}$ tablets without TMC had a similar value $(80 \%)$ at the designated time points. A negatively charged drug (CHC) showed more drug release from the formulated tablet than a positively charged drug (HBB). It might be that the chemical structure of the drug has a major role in the dissolution profile, while the charge of the drug has a minor effect on drug release. In this study, purified water was used as a dissolution medium for CHC and HBB tablets. This was due to the USP dissolution medium for the $\mathrm{CHC}$ tablet being water [16]. An acidic and alkaline solution will be used as a dissolution medium for the $\mathrm{CHC}$ and $\mathrm{HBB}$ tablets in further studies because tablets formulated 
http://wjst.wu.ac.th

with TMC might significantly improve acidic or alkaline environments regarding their drug dissolution or drug release patterns.

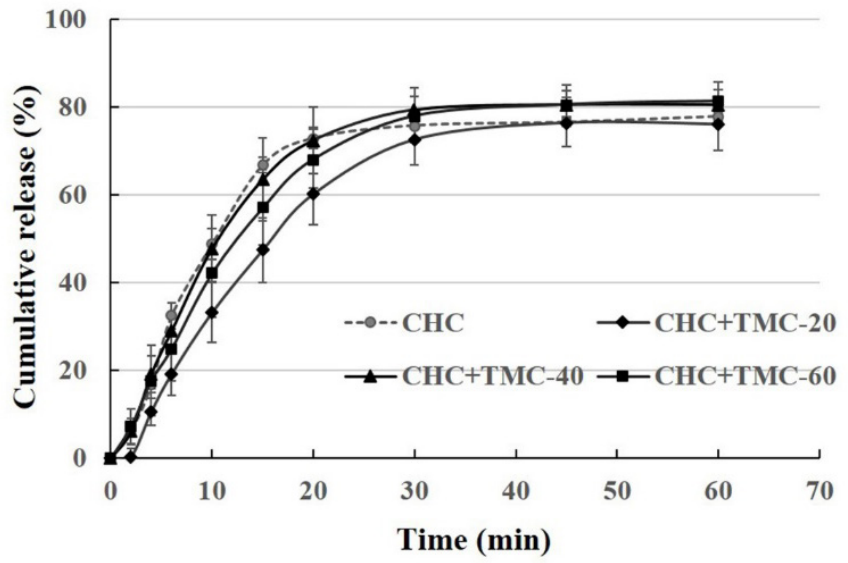

(a)

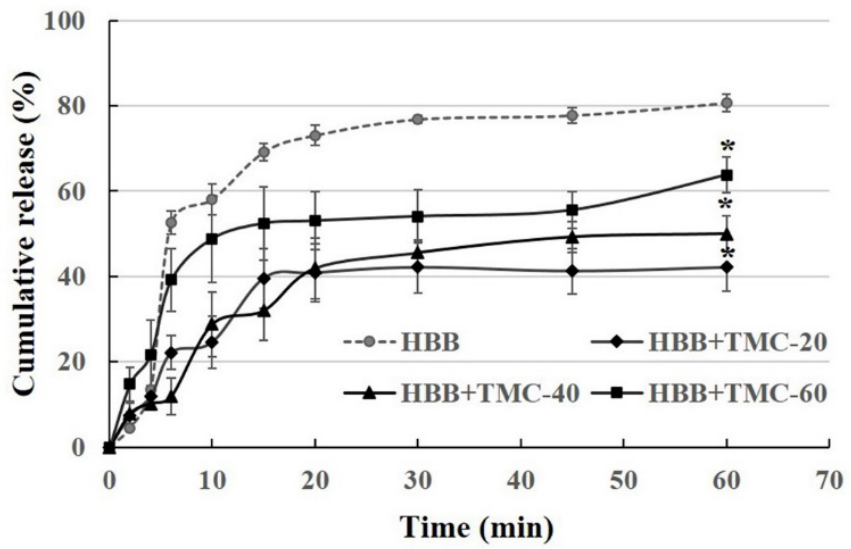

(b)

Figure 3 Dissolution profiles of the CHC (a) and HBB (b) from the tablets formulated without TMC and with TMC-20, TMC-40 and TMC-60. Significant differences with the tablet formulated with the presence of TMC (control) are designated as $*(p<0.05)$.

\section{Conclusions}

This study revealed that the DQ of TMC seemed not to affect the properties of the prepared tablets, except the dissolution profiles. Using purified water as the dissolution medium, TMCs had a minor retarding effect on the dissolution of a positively charged drug, i.e., CHC. However, they showed a significant retard of the dissolution of a negative charged drug, i.e., HBB. When a comparison was made among TMC with various DQ, TMC with DQ of $60 \%$ showed a higher drug release from the formulated tablets, which is dependent on parameters like water solubility, MW, and viscosity. 
http://wjst.wu.ac.th

\section{Acknowledgments}

The authors would like to acknowledge the School of Pharmaceutical Sciences, University of Phayao, Thailand for the financial support. We would also like to express our thanks to the Faculty of Pharmaceutical Sciences, Naresuan University for providing necessary instruments.

\section{References}

[1] D Dahlgren and H Lennernäs. Intestinal permeability and drug absorption: Predictive experimental, computational and in vivo approaches. Pharmaceutics 2019; 11, 411.

[2] B Shekhawat P and VB Pokharkar. Understanding peroral absorption: Regulatory aspects and contemporary approaches to tackling solubility and permeability hurdles. Acta. Pharm. Sin. B 2017; 7, 260-80.

[3] VK Mourya and NN Inamdar. Trimethyl chitosan and its applications in drug delivery. J. Mater. Sci. Mater. Med. 2009; 20, 1057-79.

[4] TMM Ways, WML Lau and VV Khutoryanskiy. Chitosan and its derivatives for application in mucoadhesive drug delivery systems. Polymers 2018; 10, 1-37.

[5] AF Kotzé, HL Luessen, BJ de Leeuw, BG de Boer, JC Verhoef and HE Junginger. N-trimethyl chitosan chloride as a potential absorption enhancer across mucosal surfaces: In vitro evaluation in intestinal epithelial cells (Caco-2). Pharm. Res.1997; 14, 1197-202.

[6] JH Hamman, CM Schultz and AF Kotzé. N-Trimethyl chitosan chloride: Optimum degree of quaternization for drug absorption enhancement across epithelial cells. Drug. Dev. Ind. Pharm. 2003; 29, 161-72.

[7] AF Kotzé, HL Leußen, AG de Boer, JC Verhoef and HE Junginger. Chitosan for enhanced intestinal permeability: prospects for derivatives soluble in neutral and basic environments. Eur. J. Pharm. Sci. 1999; 7, 145-51.

[8] W Wang, Q Meng, Q Li, J Liu, M Zhou, Z Jin and K Zhao. Chitosan derivatives and their application in biomedicine. Int. J. Mol. Sci. 2020; 21, 487.

[9] MM Thanou, AF Kotzé, T Scharringhausen, HL Luessen, AG de Boer, JC Verhoef and HE Junginger. Effect of degree of quaternization of $\mathrm{N}$-trimethyl chitosan chloride for enhanced transport of hydrophilic compounds across intestinal caco-2 cell monolayers. J. Control. Release. 2000; 64, 15-25.

[10] MS Arayne, N Sultana, FA Siddiqui. Determination and quantification of cetirizine $\mathrm{HCl}$ in dosage formulations by RP-HPLC. Pak. J. Pharm. Sci. 2005; 18, 7-11.

[11] P Katewongsa, K Terada and T Phaechamud. Spatial distributing lubricants from Raman mapping and scanning electron microscopy-energy dispersive X-ray spectroscopy on cetirizine dihydrochloride fast disintegrating tablet properties. J. Pharm. Investig. 2017; 47, 249-62.

[12] APG Nikalje, R Gadikar and S Turwale. A simple stability indicating HPLC method for simultaneous determination of levocetirizine dihydrochloride, phenylephrine hydrochloride and paracetamol in pharmaceuticals. Int. J. Pharm. Sci. Res. 2019; 10, 2497-503.

[13] C Chen. Physicochemical, pharmacological and pharmacokinetic properties of the zwitterionic antihistamines cetirizine and levocetirizine. Curr. Med. Chem. 2008; 15, 2173-91.

[14] LA Samuels. Pharmacotherapy update: Hyoscine butylbromide in the treatment of abdominal spasms. Clin. Med. Ther. 2009; 1, 647-55.

[15] AA Gouda. Kinetic spectrophotometric determination of hyoscine butylbromide in pure form and in pharmaceutical formulations. Arab. J. Chem. 2010; 3, 33-8.

[16] B Shekhawat P and BV Pokharkar. Understanding peroral absorption: Regulatory aspects and contemporary approaches to tackling solubility and permeability hurdles. Acta Pharm. Sin. B 2017; 7, 260-80.

[17] W Boonyo, HE Junginger, N Waranuch, A Polnok and T Pitaksuteepong. Chitosan and trimethyl chitosan chloride (TMC) as adjuvants for inducing immune responses to ovalbumin in mice following nasal administration. J. Control. Release 2007; 121, 168-75. 
http://wjst.wu.ac.th

[18] W Boonyo. 2010, Effect of the degree of quaternization and molecular weight of trimethyl chitosan for enhancing the immune responses after nasal vaccination. Ph. D. Dissertation. Naresuan University, Phitsanulok, Thailand.

[19] The United State Pharmacopeial Convention. The United States pharmacopeia 2018: USP 41; The national formulary: NF 36. United Book Press, Maryland, 2018.

[20] I Brondz, A Brondz. British Pharmacopoeia. Vol. I-III. Her Majesty's Stationery Office (HMSO), London, 2015.

[21] M Masuelli. Mark-Houwink parameters for aqueous-soluble polymers and biopolymers at various temperatures. J. Polym. Biopolym. Phys. Chem. 2014; 2, 37-43.

[22] S Boontha, HE Junginger, N Waranuch, A Polnok and T Pitaksuteepong. Formation of particles prepared using chitosan and their trimethyl chitosan derivatives for oral vaccine delivery: Effect of molecular weight and degree of quaternization. Songklanakarin J. Sci. Technol. 2010; 32, 363-71.

[23] SB Kiran, SD Ravindra, C Bhaskar, P Anant and SK Shivajirao. Effect of oppositely charged polymer and dissolution medium on swelling, erosion, and drug release from chitosan matrices. AAPS PharmSciTech 2007; 8, E1-E9.

[24] O Phongwarin, P Wongchan-udom, P Rewsuwan, W Boonyo, S Boontha and T Pitaksuteepong. Influence of trimethyl chitosan on dissolution of charged drugs from oral solid dosage forms. $J$. Interdiscipl. Network. 2013; 2, 65-70. 